18 Font, R. L., and Naumann, G., Archives of Ophthalmology, 1969, 82, 784. 1 Loman, J., Dameshek, W., Myerson, A., and Goldman, D., Archives of Neurology and Psychiatry, 1936, 50, 510 .

20 Behrman, S., British fournal of Ophthalmology, 1967, 51, 269.

21 Duane, T. D., Archives of Ophthalmology, 1954, 51, 343.

22 Earl, C. J., Transactions of the Ophthalmological Societies, 1964, 84, 215.

${ }^{23}$ Nelson, D. A., Jeffreys, W. H., and McDowell, F., Archives of Neurology,

$1958,79,31$.
${ }^{24}$ Rucker, C. W., and Kearns, T. P., American fournal of Ophthalmology, $1961,51,15$.

${ }^{25}$ Cogan, D. G., Archives of Ophthalmology, 1961, 66, 180

${ }_{26}$ Robinson, J. L., fournal of Neurosurgery, 1972, 36, 83.

\section{Pollution in the Operating Theatre}

Though the occupational hazard to industrial workers from the inhalation of the noxious vapours of solvents such as trichloroethylene, benzene, or carbon tetrachloride is well known, the possibility of a similar risk for those working in the atmosphere of an operating theatre is less so. The suggestion that even this atmosphere might affect people's health has recently received some attention in Scandinavia and America.

The particular aspect of ill health studied in two recent reports concerned the incidence of spontaneous abortion among married women working in operating theatres. By means of a questionnaire V. Askrog and B. Harvald, ${ }^{1}$ in Copenhagen, found that among nurse anaesthetists there were 10 abortions plus perinatal deaths out of 85 pregnancies $(12 \%)$ before they entered this employment, and there were 44 out of $229(19 \%)$ after they entered it. The difference is not significant at the $5 \%$ level, but when similar figures for women anaesthetists and even the wives of men anaesthetists (which showed a similar disparity) were added in, the result was a significant difference at the $0.1 \%$ level. Out of 212 pregnancies before employment in anaesthetics 21 ended in abortion or perinatal death $(10 \%)$, whereas out of 392 pregnancies afterwards 80 ended in abortion of perinatal death $(21 \%)$. There was also a significantly greater number of premature deliveries among the women who gave birth after taking up anaesthetic work. A study at Stanford University School of Medicine in California gave similar results to the Danish one. E. N. Cohen and colleagues ${ }^{2}$ obtained information by personal interview from 67 operating-room nurses and 92 general duty nurses, and found that in 1966-70 30\% of pregnancies in the first group ended in spontaneous miscarriage, while $9 \%$ in the control group did so. By means of questionnaires they obtained confirmatory figures in a comparison between practising anaesthetists and doctors in other specialties. In both these series the women at risk were a little more than three years older than the control group, and there may also have been undisclosed differences between them. Despite these doubts the statistical differences found between those exposed and those not exposed to the atmosphere of the theatre is notable.

Apart from these reports about specific effects many people who work in operating theatres experience the discomfort of a stuffy atmosphere. Anaesthetists in particular are well aware of the consequences of a long day spent in close proximity to their patients' expired breath. There is a widespread, if vague, feeling among them that headache and fatigue, resulting perhaps in inattention, are common in poorly ventilated theatres. ${ }^{3}$ In addition it is known that anaesthetists absorb measurable amounts of anaesthetics. Occasionally these may be sufficient to show up an existing illness. Two anaesthetists are reported to have developed sensitivity to halothane, suffering jaundice as a result of their occupational exposure. ${ }^{4}$ A nurse-anaesthetist developed signs of myasthenia gravis after administering methoxyflurane but was unaffected by some other drugs. 5 There is also the possibility that the incidence of malignant tumours of lymphoid tissue is higher in anaesthetists than in the general population. ${ }^{6}$

Anaesthetic drugs are potent poisons. In experimental animals some of them are teratogenic, but only after long exposure to concentrations within the range used clinically in man. Similarly, fetal death can be produced in experimental animals. In man it has proved impossible to determine the incidence of teratogenic effects or abortion after anaesthesia and surgery.

The reports about abortion provide some evidence of a possible occupational hazard, but more information is needed and is being sought. Whatever conclusion is reached on the validity of these data, there seems to be enough evidence already to suggest that a general improvement in the standards of ventilation of operating theatres, with removal of anaesthetic and other gases or vapours, is urgently required. Perhaps in addition anaesthetists and nurses should spend only limited periods of time in the operating theatre.

1 Askrog, V. F., and Harvald, B., Nordisk Medicin, 1970, 83, 498.

2 Cohen, E. N., Bellville, J. W., and Brown, B. W., Anesthesiology, 1971, 35,

s Whitcher, C. E., Cohen, E. N., and Trudell, J. R., Anesthesiology, 1971, 35, 348 .

35, 348.
Klatskin, G., and Kimberg, D. V., New England Fournal of Medicine, 1969,

280, 515.
5 Elder, B. F., Beal, H., DeWald, W., and Cobb, S., Anesthesia and Analgesia, 1971, 50, 383 .

6 Bruce, D. L., Eide, K. A., Linde, H. W., and Eckenhoff, J. E., Anesthesio$\log y, 1968,29,565$

\section{Chondromalacia Patellae}

The term chondromalacia patellae is used to denote a condition affecting fit persons in which pain arises from the posterior aspect of the patella. The earliest recognized account of the clinical condition ${ }^{1}$ described changes in the cartilage of the patella which were thought to be due to trauma, and despite a later account of 640 cases $^{2}$ in which evidence for trauma was found in two-thirds the exact cause of the syndrome remains a mystery.

Disorders of the cartilage on the posterior aspect of the patella give rise to characteristic symptoms and physical signs. The main symptom is of pain in the region of the patella, sometimes associated with a sensation of "givingway" or "locking"- though these seldom actually occur. The pain is worst when the quadriceps muscle contracts most strongly, notably when descending stairs or rising from a chair. The knee itself may look quite normal, though quadriceps wasting is frequent and joint effusions have been described. The range of movement is full. The posteromedial and posterolateral aspects of the patella can be palpated when it is displaced and are tender, and clinical tests involving compression of the patella against the femoral condyles are painful. Radiographs are usually normal, 